\title{
Should Species Distribution Models Account for Spatial Autocorrelation? A Test of Model Projections Across Eight Millennia of Climate Change
}

\section{Citation}

Record, Sydne, Matthew C. Fitzpatrick, Andrew 0. Finley, Sam Veloz, and Aaron Ellison. Forthcoming. Should species distribution models account for spatial autocorrelation? A test of model projections across eight millennia of climate change. Global Ecology and Biogeography:12017.

\section{Published Version}

doi:10.1111/geb.12017

\section{Permanent link}

http://nrs.harvard.edu/urn-3:HUL.InstRepos:10385407

\section{Terms of Use}

This article was downloaded from Harvard University's DASH repository, and is made available under the terms and conditions applicable to Other Posted Material, as set forth at http:// nrs.harvard.edu/urn-3:HUL.InstRepos:dash.current.terms-of-use\#LAA

\section{Share Your Story}

The Harvard community has made this article openly available.

Please share how this access benefits you. Submit a story. 
1 Running title: Projecting spatial species distribution models

2

3

$4 \quad$ Should species distribution models account for spatial autocorrelation? A test of model projections across eight millennia of climate change

7

8 Sydne Record $^{1}$, Matthew C. Fitzpatrick ${ }^{2}$, Andrew O. Finley ${ }^{3}$, Sam Veloz $^{4}$, and Aaron M. Ellison ${ }^{1}$ 9

${ }^{1}$ Harvard Forest, Harvard University, Petersham, MA

$11{ }^{2}$ Appalachian Lab, University of Maryland Center for Environmental Science, Frostburg, MD

$12{ }^{3}$ Departments of Forestry and Geography, Michigan State University, East Lansing, MI ${ }^{4}$ PRBO Conservation Science, Petaluma, CA

14

15 Key words: Bayesian, historical validation, spatial random effect, paleoecology

16

$17 *$ Corresponding author's email: srecord@fas.harvard.edu

18 Article type: Research Paper 


\section{ABSTRACT}

20 Aim The distributions of many organisms are spatially autocorrelated, but it is unclear whether

21 including spatial terms in species distribution models (SDMs) improves projections of species

22 distributions under climate change. We provide one of the first comparative evaluations of the

23 ability of a purely spatial SDM, a purely non-spatial SDM, and a SDM that combines spatial and

24 environmental information to project species distributions across eight millennia of climate

25 change.

26 Location Eastern North America.

27 Methods To distinguish between the importance of climatic versus spatial explanatory variables,

28 we fit three Bayesian SDMs to modern occurrence data for Fagus and Tsuga, two tree genera

29 whose distributions can be reliably inferred from fossil pollen: a spatially-varying intercept

30 model, a non-spatial model with climatic variables, and a spatially varying intercept plus climate

31 model. Using high temporal resolution paleoclimate data, we hindcasted the SDMs in 1,000 year

32 time steps for 8000 years, and compared model projections with palynological data for the same

33 periods.

34 Results For both genera, spatial SDMs provided better fits to the calibration data, more accurate

35 predictions of a hold-out validation dataset of modern trees, and higher variance in current

36 predictions and hindcasted projections than non-spatial SDMs. Performance of non-spatial and

37 spatial SDMs according to the Area Under the Curve of the Receive Operating Curve varied by

38 genus. For both genera, false negative rates between non-spatial and spatial models were similar,

39 but spatial models had lower false positive rates than non-spatial models. 
40 Main conclusions The inclusion of computationally demanding spatial random effects in SDMs

41 may be warranted when ecological or evolutionary processes prevent taxa from shifting their

42 distributions or when the cost of false positives is high. 


\section{INTRODUCTION}

44 The last decade has witnessed a marked increase in the application of models that project the

45 potential geographic distributions of species by linking observations of species occurrences to

46 environmental predictor variables. These models, commonly called bioclimatic envelope,

47 ecological niche, or species distribution models (hereafter SDMs), are important tools for

48 forecasting impacts of climatic change on biological diversity and for generating conservation

49 plans and climate-change policy (Guisan \& Thuiller, 2005). To project future distributions under

50 different, plausible scenarios of climatic change, SDMs use statistical relationships between

51 present-day distributions of species and climate (Elith et al., 2010). Although generally

52 successful at explaining and predicting current distributions of species (Franklin \& Miller, 2009),

53 impact assessments derived from SDMs have been criticized for their reliance on a number of

54 largely untested ecological assumptions, methodological issues, and statistical concerns (e.g.,

55 Pearson \& Dawson, 2003; Dormann, 2007).

56 Chief among these issues is the failure of most SDMs to account for spatial dependence

57 of occurrence data (Gelfand et al., 2006; Bahn and McGill, 2007; Dormann, 2007; Elith et al.,

58 2010). Spatial autocorrelation arises in ecological data because nearby points tend to be more

59 similar, in physical characteristics and/or species occurrences or abundances, than are pairs of

60 locations that are farther apart (Legendre, 1993). When model assumptions about independent

61 and identically distributed residuals are violated, there could be a bias in the regression

62 parameter estimates, potentially leading to poor inference. Studies illustrate that failure to

63 account for spatial autocorrelation can lead to misidentification of important driving variables

64 and overly optimistic error rates (e.g., Lichstein, et al., 2002; Segurado et al., 2006; Diez \&

65 Pulliam, 2007; Dormann, 2007), especially when small-scale patterns of explanatory variables 
66

67

68

69

70

71

72

73

74

75

76 77 parameterized with current conditions (Pearman, et al., 2008a; Nogués-Bravo, 2009; Dobrowski

create instability in broad-scale regression parameter estimates (Hawkins et al., 2007). Further, models based solely on spatial interpolation can provide better fits to species range data than models based on explanatory environmental variables (Bahn \& McGill, 2007), suggesting that spatial autocorrelation in unmeasured factors (e.g., population processes such as dispersal or underlying resources such as soil moisture) may account for most of the observed distributional patterns.

Analysis of spatial SDMs primarily has focused on predicting current or simulated species' distributions using a hold-out dataset for model validation (Gelfand et al., 2006; Wilson et al., 2010), but projections of spatial SDMs in changing climates over long time scales remain largely untested. Observed changes in species distributions as a result of past climatic dynamics provide a unique opportunity to compare projections of spatial and non-spatial SDMs et al., 2011, Veloz et al., 2012).

79 etal., 2011, Veloz etal., 2012).

Projections to environmental conditions different from those used to calibrate SDMs are subject to error (Heikkinen et al., 2006) and may not be ecologically meaningful or statistically valid if there are changes in correlations between variables across time and space (Elith et al., 2010) or if species-environment relationships are not conserved (e.g., Fitzpatrick et. al., 2007, Veloz et al., 2012). It also is not known whether it is desirable to project models with spatial random effects based on the partially observed spatial distribution of a species at one time point into a new temporal domain.

In this study, we developed non-spatial and spatial SDMs for two genera of trees in eastern North America. We calibrated the models with current climate data and Forest Inventory and Analysis (FIA) data collected by the United States Forest Service. We then projected the 
models back in time using paleoclimate simulations and extensive pollen records as independent validation data. Our approach is similar to that of Pearman et al. (2008a), who used fossil pollen

to validate SDMs of European trees projected back to a single time in the mid-Holocene $(6,000$ years before present). However, the availability of new paleoclimate reconstructions, which provide millennial snapshots of historic climate for the last 21,000 years before present, allowed us to validate the models at a much finer temporal resolution.

To assess the usefulness of adding a spatial term to SDMs we consider the following: 1) a spatially-varying intercept model with no climate variables; 2) a non-spatial model with climate variables; and 3) a spatially-varying intercept model with climate variables. As detailed in the Methods Section and Appendix S3, the spatially-varying intercept was introduced via spatial random effects. The rationale for choosing these candidate models is a follows. If climate variables describe a significant portion of the variability in the observed distribution and if these variables change over time, then projections from models with climatic variables will show a conservative shift away from the observed distribution. For the spatially varying intercept model with climate variables, any projected shifts in distributions are tempered by the spatial random effects. Depending on the amount of spatial autocorrelation, spatial random effects act to draw the projected distribution back toward the observed distribution used to calibrate the model. If climate variables do not describe a significant portion of the variability in the observed distribution, then the spatial random effects will keep projected distributions close to the observed distribution, i.e., the only learning for prediction will come from the observed distribution and hence projected probability of species occurrence will be similar to the observed probability of occurrence. With these three candidate models, we were able to tease apart differences due to the spatial random effects alone, the climate variables alone, and their additive 
112 effects. We parameterized and estimated model parameters following a Bayesian framework,

113 which provided full posterior distributions for model parameters and allowed us to estimate the

114 uncertainty in our statistical inferences. We focus on two tree genera, Fagus and Tsuga, whose

115 distributions can be readily inferred from fossil pollen and which possess contrasting life

116 histories.

117 We address three questions. (1) Do non-spatial SDMs of current distributions of Fagus

118 and Tsuga based on climate variables exhibit residual spatial autocorrelation? (2) Do SDMs with

119 spatial random effects that include or exclude climate variables provide better fits to the observed

120 distributions than non-spatial SDMs with climate variables only? (3) Do hindcasted spatial

121 SDMs better predict historic distributions than non-spatial SDMs?

122 Methods

123 Study genera

124 We studied two tree genera, Fagus and Tsuga. In eastern North America, Fagus is represented by 125 only one species, F. grandifolia (Ehrh.) (American Beech), and Tsuga by only two, the 126 widespread T. canadensis (L.) Carr. (Eastern Hemlock), and the narrow endemic T. caroliniana

127 Engelm.) (Carolina Hemlock). For both Fagus and Tsuga, the relationship between local

128 abundance of trees and relative abundance of pollen in sediment cores has already been derived

129 (Davis, 1981). Tsuga is a conifer with passively-dispersed cones, whereas Fagus is deciduous

130 with animal-dispersed seeds.

\section{Occurrence data}

132 We used FIA data to describe the current distribution of Fagus and Tsuga. In every 2428 ha of

133 land in the United States classified "forested", there is one permanent FIA plot, each containing

134 four $7.2 \mathrm{~m}$ fixed-radius subplots (Woudenberg et al., 2010). In each subplot, all trees $>12.7 \mathrm{~cm}$ 
135 diameter at breast height have been measured periodically since the 1940s; consistent nationwide 136 annual inventories were initiated in 2001 . We used data from the most recent full plot inventory 137 (2003 - 2008) to calibrate our models.

138 Historic distributions of Fagus and Tsuga were derived from fossil pollen data in the 139 Neotoma Paleoecology Database (<www.neotomadb.org〉). Paleoclimate data (described below)

140 were available at 1 kiloannum before present $(\mathrm{kaBP})$ intervals from 0-21 kaBP, so we focused on 141 millennial historic distributions of Fagus and Tsuga. Given the variation in temporal scale and

142 spatial resolution across study sites and uncertainties associated with radiocarbon aging of pollen

143 from sediment cores (Blauw et al., 2007), we compiled pollen datasets in which Fagus and

144 Tsuga were counted as present at a site if their pollen percentages reached threshold levels at any

145 time within 500 years centered on each historic millennium (Appendix S1). We chose a 500 year

146 window because cross-validation analyses of biostratigraphic ages from recently revised age

147 models for all pollen sites suggested that 500 years is a conservative estimate of temporal

148 uncertainty for sites in the Neotoma database (Blois et al., 2011). To determine the sensitivity of

149 historic tree distributions to the pollen percentage thresholds used to define a genera's presence

150 or absence at a site, we specified low and high thresholds for each genus (Pearman et al., 2008a):

$1510.5 \%$ or $1 \%$ for Fagus and 1\% or 2\% for Tsuga (Davis, 1981).

152 Extent and resolution

153 The extent of the study area was the portion of eastern North America with the highest density of

154 pollen data (Fig. 1). This region contained 75,251 FIA sites and up to 379 Neotoma locations,

155 depending on time period considered. Paciorek \& McLachlan (2009) found that spatial patterns

156 relating current and past climates to abundances of pollen and trees were unreliable at resolutions

157 below $\sim 50 \mathrm{~km}$, so the climatic predictors for our model (see below) were downscaled to a 
158 resolution of 0.5 -degrees $(\sim 50-80 \mathrm{~km}$ depending on latitude). We upscaled the current tree

159 occurrence data for each grid cell in the climate spatial data layers, keeping track of the number

160 of FIA sites per 0.5-degree cell to be used as weights in the models (Appendix S2). Following

161 this aggregation there were a total of 1,419 FIA observations with presence/absence ratios for

162 Fagus and Tsuga of 706/713 and 380/1,039, respectively. The number of aggregated pollen

163 observations varied for each $1 \mathrm{kaBP}$ time period (Fig. 2). Although both paleoclimatic and pollen

164 data extended back $21 \mathrm{kaBP}$, the total sample size and the number of pollen grains of each genus

165 declined rapidly beyond 8 kaBP (Fig. 2). Thus, our hindcast projections extend only from 1 to 8

$166 \mathrm{kaBP}$, which allowed us to validate the models using a minimum of 200 grid cells containing

167 observations, and at least 50 of which contain presences for each genus.

168 Climate data

169 Modern climate data came from the observed dataset of the Climate Research Unit (CRU),

170 University of East Anglia (Brohan et al., 2006). Paleoclimate data for this study came from a

171 recent transient simulation of the CCSM3 global circulation model (GCM) (Liu et al., 2009).

172 The standard change-factor approach was employed to statistically downscale and reduce bias in

173 the climate data (Wilby et al., 2004). For each climate variable at each millennial interval, the

174 difference between modeled paleoclimate and modeled modern climate was calculated and then

175 resampled to a $0.5 \times 0.5$-degrees grid to match the resolution of the CRU observed climate

176 dataset (Mitchell \& Jones, 2005).

177 Decadal averages of seasonal variables were the highest temporal resolution data

178 available from the archived CCSM3 simulations. To get a 'snapshot' of climatic conditions at

179 each millennial time point, decadal averages of seasonal climate variables from the CRU or

180 CCSM3 simulations were calculated for the first 100 years of each millennium (e.g., 8.0 to 7.9 
$181 \mathrm{kaBP})$. Because summaries of modern observed climate are available at centennial scales, these

182 same centennial summaries of paleoclimate were derived to aid comparisons between paleo and

183 modern SDMs. Bioclimatic variables that captured precipitation and temperature averages and

184 seasonalities were used because response surface analyses for Fagus and Tsuga have shown that

185 climatic annual averages, annual ranges, and seasonality were important factors controlling the

186 Holocene migrations of these genera (Bartlein et al., 1986). Specifically, we calculated six

187 bioclimatic variables (Hijmans et al., 2005): annual mean temperature (BIO1), mean diurnal

188 range $(\mathrm{BIO} 2)$, temperature seasonality $(\mathrm{BIO} 4)$, temperature annual range (BIO7), annual

189 precipitation (BIO12), and precipitation seasonality (BIO15).

190

Two of the six calculated bioclimatic variables, temperature seasonality and temperature

191 annual range, had within-time correlations with the other bioclimatic variables $\geq 0.7$, so they were

192 not included as explanatory variables in the models that included environmental predictors (see

193 Appendix S3). The correlations between mean diurnal range and annual precipitation varied

194 between modern and historic times (see Appendix S3), and such changing correlation structures

195 between times could be problematic when projecting models beyond the present (Elith et al.,

196 2010). To determine if sufficient variance in the current distribution was explained by the two

197 remaining variables with stable correlation structures over time (i.e., annual mean temperature

198 and precipitation seasonality), we compared a model with annual mean temperature,

199 precipitation seasonality, mean diurnal range, and annual precipitation with another that included

200 only annual mean temperature and precipitation seasonality.

201 Model calibration

202 We used Bayesian generalized linear models (GLMs) to model genera occurrence. While

203 approaches such as neural networks and genetic algorithms have been used for SDMs and 
204 although model projections can be sensitive to the type of statistical model employed (Elith $e t$ 205 al., 2010), classical approaches do not provide the statistical inferences we sought. Even though

206 GLMs describe a central tendency and not a limiting effect (e.g., of temperature or precipitation

207 extremes), Bayesian spatial GLMs provide exact inference for the random model parameters,

208 including spatial random effects, by estimating entire posterior distributions at both observed and

209 unobserved geographic locations (Gelfand et al., 2006). Because our goal was to compare

$210 \mid$ consistently SDMs with three different specifications (i.e., spatially--varying intercept only

211 (SVI), climate only, and spatially-varying intercept plus climate), we adopted a Bayesian

212 approach in fitting all of the models. Model structure is detailed in Appendix S2; model code is

213 provided in Appendix S4.

214 Including the SVI has a potential for overfitting as it allows variable intercepts for every

215 location and thus a very flexible spatial fit to the FIA data. As a null model, we also fit a

216 multilevel B-Spline to the FIA data (Lee et al., 1997) using the 'MBA' package of 'R' statistical

217 software to determine whether our hindcasting test for the inclusion of a SVI in the Bayesian

218 models was sufficient. As an exploratory analysis into the strength of the residual spatial

219 dependence in the FIA data, we calculated Moran's I from the residuals of the non-spatial GLMs.

220 This latter analysis was conducted using the Spatial Analyst Tool in ArcMap10 (ESRI, 2011).

\section{Model fit to calibration data}

222 We fit the Bayesian models to $90 \%$ of the FIA data $(N=1,277)$ and randomly selected a

$22310 \%$ holdout dataset $(N=142)$ to assess predictive performance. We also used DIC to rank the

224 Bayesian models fit to the calibration data (Spiegelhalter et al., 2002). DIC is the sum of the

225 Bayesian deviance (a measure of model fit) and the effective number of parameters (a penalty for 
model complexity). Lower DIC values indicate better model fit. Models are compared using

227 ADIC:

228

$$
\Delta \mathrm{DIC}_{i}=\mathrm{DIC}_{i}-\min (\mathrm{DIC})
$$

229 where min(DIC) is the DIC value for the model with the best fit (i.e., lowest DIC value). In

230 general, $\Delta \mathrm{DIC}<2$ indicates weak evidence, $5<\Delta \mathrm{DIC}<10$ indicates strong evidence, and $\Delta \mathrm{DIC}$

$231>10$ indicates very strong evidence that one model is preferred over another (Spiegelhalter et al.,

232 2002).

233 FIA hold-out dataset and pollen validations

234 When projecting the spatial models back in time for the pollen validation, the random effects

235 serve to draw the projected distributions for each genus back toward that of the observed

236 distribution used for model calibration (i.e., the FIA data) in the new time period (Appendix S2).

237 To compare the performance of the models in predicting current and projecting past distributions,

238 three measures were calculated using the 'ROCR' package of 'R' statistical software: the Area

239 Under the Curve (AUC) of a Receiver Operating Curve (ROC), false negative rates (FNR), and

240 false positive rates (FPR). The calculation of FNRs and FPRs requires converting the continuous

241 outputs to a binary form using a threshold, in this case the value that maximizes the sum of

242 sensitivity and specificity (Liu et al., 2005; Lobo et al., 2008).

243 Differences in AUC, FNR, and FPR between models, genera, pollen percentage

244 thresholds, time, and the model $\times$ genus interaction were tested with three GLMs. To normalize

245 residuals and reduce heteroskedasticity, AUC, FNR, and FPR were all arcsin transformed.

246 Model, genera, pollen percentage threshold, and the model $\times$ genus interaction entered the GLM

247 as fixed factors, and time entered as a covariate. The model $\times$ genus interaction was of particular

248 interest as it tested whether or not different models performed better or worse in hindcasting the 
249 presence-absence of the two genera. The data were analyzed with separate GLMs for AUC, FNR,

250 and FPR to facilitate the interpretation of Tukey's Honest Significant Differences post-hoc

251 comparisons at the expense of increasing Type II error rates. Bonferroni corrections of the $P$ -

252 values from the tests did not alter the significance of any of the effects.

\section{Results}

254 Parameter estimates and model fit to calibration data

255 In non-spatial models with two climatic variables (i.e., annual mean temperature and

256 precipitation seasonality) or four climatic variables (i.e., annual mean temperature, mean diurnal

257 range, annual precipitation, and precipitation seasonality), all climatic variables were significant

258 predictors of presence/absence: none of the $95 \%$ credible intervals of the parameter estimates

259 included zero (Tables 1, 2). In contrast, in the spatial models some of the climatic explanatory

260 variables were not significant predictors of presence/absence (e.g., annual mean temperature in

261 the Tsuga models with two climatic variables and mean diurnal range in the Fagus model with

262 four climatic variables; Tables $1 \& 2$ ). Changes in the magnitude and sign of parameter estimates

263 between non-spatial and spatial models suggested that non-spatial models violated the

264 assumption of independent identically distributed residuals. The residuals of the non-spatial

265 models for both Fagus and Tsuga also exhibited significant positive spatial autocorrelation

266 (Moran's I = 0.604, $P<1 \times 10^{-7}$ for Fagus; Moran's I $=0.761, P<1 \times 10^{-7}$ for Tsuga),

267 supporting the conclusion that non-spatial models were inappropriate for these data.

268 For Fagus, the SVI plus climate model with annual mean temperature and precipitation

269 seasonality had the lowest DIC value and $\Delta \mathrm{DIC}>10$ relative to all other Fagus models (Table 3,

270 Fig. 3). In contrast, for Tsuga, the SVI model with no bioclimatic predictors had the lowest DIC

271 value and $\Delta \mathrm{DIC}>10$ relative to all other Tsuga models (Table 3, Fig. 4). 
The non-spatial SDMs for both Fagus and Tsuga that included only annual mean

273 temperature and precipitation seasonality had $\Delta \mathrm{DIC}$ values $>10$ relative to the non-spatial models

274 that included annual mean temperature, precipitation seasonality, mean diurnal range, and annual

275 precipitation (Table 3). Given that the correlative relationship between mean diurnal range and

276 annual precipitation was unstable between modern and historic times (see Appendix S3) and that

277 the inclusion of them did not provide a large decrease in the $\Delta \mathrm{DIC}$, these two climatic variables

278 were excluded from the models used for prediction that were validated with the $10 \%$ holdout FIA

279 dataset and fossil pollen record.

280 FIA hold-out dataset and pollen validations

281 For the contemporary 10\% hold-out FIA dataset for both genera, the non-spatial model

282 performed worse than the SVI, SVI plus climate, or multilevel B-Spline models in terms of

283 AUC, FNR, and FPR (Table 4; Appendix S5). However, the same was not true when models

284 were hindcasted. Based on AUC, there were significant main effects of model type (non-spatial,

285 SVI, SVI plus climate, FIA B-Spline; $F_{3,118}=32.4, P=2.4 \times 10^{-15}$ ), and a significant genus $\times$

286 model interaction $\left(F_{3,118}=13.8, P=8.8 \times 10^{-8}\right)$ (Table 4, Appendix S5) on model performance.

287 For the Fagus hindcasts, on average the non-spatial model had higher AUC values than the 288 spatial models (i.e., SVI and SVI plus climate) and FIA multilevel B-spline models, but the 289 opposite was true for Tsuga. The FNRs in the hindcasting validation varied by model $\left(F_{3,118}=\right.$ $2908.1, P=6.2 \times 10^{-5}$ ). The FIA data multilevel B-spline model had the highest FNR and post-hoc 291 comparisons showed that there were no significant differences between the non-spatial and 292 spatial models in FNRs (Table 4, Appendix S5). Similar to the FNRs, the FPRs also varied by $293 \operatorname{model}\left(F_{3,118}=9.0, P=1.95 \times 10^{-5}\right)($ Table 4, Appendix S5). The FIA data multilevel B-spline 294 and the non-spatial models had higher FPRs than the spatial models. There were no significant 
genus $\times$ model interactions for FNRs $\left(F_{3,118}=2.3, P=0.08\right)$ and FPRs $\left(F_{3,118}=1.7, P=0.18\right)$.

296 Overall for the three measures, model performance worsened as models were projected further

297 back in time (AUC: $F_{1,118}=118, P=2.0 \times 10^{-6}$; FNR: $F_{1,118}=98.7, P=2.0 \times 10^{-16}$; FPR: $F_{1,118}=$ $298109, P=2.0 \times 10^{-16}$ ). Also, model performance was better (i.e., higher AUC and lower FNR and 299 FPR) for Tsuga than for Fagus (AUC: $F_{1,118}=10.0, P=0.002$; FNR: $F_{1,118}=65.5, P=5.8 \times 10^{-}$

$300{ }^{13}$; FPR: $F_{1,118}=88, P=6.3 \times 10^{-16}$ ) and for the low pollen percentage thresholds than for the 301 high pollen percentage thresholds (AUC: $F_{1,118}=14.0, P=2.8 \times 10^{-4}$; FNR: $F_{1,118}=15.3, P=1.5$ $302 \times 10^{-4}$; FPR: $F_{1,118}=24.9,2.13 \times 10^{-16}$ ). For all three test metrics (i.e., AUC, FNR, FPR), the 303 multilevel B-spline fit to the FIA data, which we used as a 'perfectly fit' model to assess whether 304 or not the spatial models were overfit to the calibration data, performed the worst. This assured 305 us that the pollen validation test was stringent enough.

\section{Discussion}

A key question regarding the application of SDMs to predicting the response of species to 308 climate change is whether the failure to include ecological and evolutionary processes (e.g., 309 dispersal, biotic interactions, readjustment lags) will prove to be problematic (reviewed by 310 Pearson \& Dawson, 2003). Depending on the species and its life history, ecological and 311 evolutionary processes may (or may not) lead to its inability to track changes in climate. While 312 there is evidence that vagile organisms (e.g., butterflies) can track rapid climate change (Warren 313 et al., 2001), sessile organisms (e.g., trees) may not readily disperse to newly suitable habitat 314 resulting in limited niche space filling (Svenning \& Skov, 2004; Meier et al., 2012). Species 315 undergoing climate driven range expansions coupled with enemy release are hypothesized to be 316 more capable of realizing their potential niche (Hellman, et al., 2012), whereas species limited 317 by a particular resource (e.g., host availability) can be constrained to the spatial distribution of 
318 the resource (Merrill et al., 2007). There is evidence that shorter-lived taxa (e.g., insects and

319 herbaceous plants; Woodward, 1990; Thomas et al., 2001) can evolve in response to rapid

320 climate change, but longer-lived taxa that cannot evolve as quickly may experience readjustment

321 lags (Pearson \& Dawson, 2003).

322 For those taxa whose distributions do not shift over time as a result of ecological and

323 evolutionary processes, the inclusion of spatial random effects in SDMs could improve

324 projections by providing a more conservative prediction of distributional shifts, especially when

325 climatic variables do not explain much variability in their observed distributions. Alternatively,

326 when climatic variables explain most of the variability in a taxon's observed distribution and the

327 taxon is capable of tracking climate, then accounting for spatial autocorrelation in SDMs won't

328 provide better projections. In other words, the spatial random effects keep the projected

329 distribution similar to the data used for model calibration, unless the covariates (e.g., climatic

330 variables) suggest otherwise. Further, if the climate variables do not explain much of the

331 variability in the observed distribution and the genera's distribution shifts far from the observed

332 distribution over time, then none of the models defined here will perform well. The predictive

333 abilities of non-spatial and spatial SDMs have rarely been compared with temporally varying

334 validation datasets to test these assertions (Gelfand et al., 2006).

335 In this study we tested the predictive abilities of non-spatial and spatial SDMs across

336 eight millennia using data from the pollen record (Appendix S1). We found that spatial SDMs

337 had better fits to the calibration data, higher predictive accuracy for a modern hold-out validation

338 dataset, and greater variance in their outputs than non-spatial SDMs (see also Gelfand et al.,

339 2006; Bahn \& McGill, 2007). For Fagus, the SVI plus climate model provided a better fit to the

340 calibration data than the SVI model, but the opposite was true for Tsuga. Also for the two 
341 climatic variable models, for Fagus there was no change in the sign of the climatic regression

342 coefficients between the non-spatial and spatial models (Table 1), but with Tsuga there was a

343 sign change in the regression coefficient for annual mean temperature between the non-spatial

344 and SVI plus climate models (Table 2). This result suggests that for Tsuga the spatial random

345 effect could be accounting for dependence in the model's residuals across space as several other

346 studies have found that parameter estimates are affected by spatial autocorrelation (Dormann,

347 2007; Kühn, 2007; Bini et al., 2009; Hodges \& Reich, 2010).

348 In the hindcasting analyses, the SVI and SVI plus climate models performed similarly.

349 This suggests that the climatic variables do not contribute much to explaining the variability of

350 occurrence relative to that explained by the spatial random effects. AUC values based on fossil

351 pollen indicated that the non-spatial model performed better for Fagus than either of the two

352 spatial models, but the opposite was true for Tsuga. However, FNR values did not differ among

353 the models for either genus, and FPR values were greater for non-spatial models for both genera.

354 We have more confidence in FNR and FPR values than in AUC values because the latter

355 describe portions of the ROC curve that are rarely encountered and weights omission and

356 commission errors equally (Lobo et al., 2008). With the pollen record, equal weighting of

357 omission and commission errors may not be ideal; we have much more confidence in the

358 presence of pollen grains than in their absence (Blauww et al., 2007; Blois et al. 2011) and false

359 negatives in the pollen record are more problematic than false positives. The lack of differences

360 in false negative rates between models shows that the non-spatial and spatial models have similar

361 FNRs.

362 Although we have less confidence in actual absences in the pollen data, the FPRs are

363 interesting when considering the ecological and evolutionary processes leading to conserved 
364 spatial structure in the distributions of species. The greater FPRs of non-spatial models for both 365 genera suggest that spatial effects may account for smaller-scale climatic spatial structure that is 366 not otherwise estimated in large-scale or averaged temperature and precipitation values (Gelfand 367 et al., 2006; Hawkins et al., 2007). Evidence from the fossil pollen and paleoclimate records 368 suggests that climatic shifts can result in abrupt ecological changes in vegetation that are driven 369 by internal dynamics, such as site-specific environmental characteristics (e.g., soil moisture) or 370 biotic interactions (e.g., competition) that create geographically localized variation in vegetation 371 composition (Williams et al., 2011). Taxon-specific responses to climate forcing also could 372 explain why the SVI model had the lowest DIC for Tsuga and why the two spatial models 373 performed better in regards to both AUC and FPR for Tsuga, but not for Fagus. Approximately 3745.5 kaBP Tsuga experienced a range contraction known as the "hemlock decline" potentially due 375 to an abrupt change in climate, a phytophagous insect infestation, or both (Bhiry \& Filion, 1996; 376 Foster et al., 2006). If the hemlock decline was due to an abrupt change in climate, then localized 377 ecological changes could have resulted in stronger spatial structure in its distribution. However, 378 decoupling changes in distributions due to climate and spatial structure due to biotic interactions 379 or site-specific abiotic characteristics is difficult because observed spatial structure is (or was) 380 inherently linked to abrupt climate change.

381 Alternatively, the spatial random effects may have captured a missing covariate, such as 382 an ecological process that generates spatial structure (Clayton et al., 1993; Paciorek, 2010). Such 383 processes could include dispersal, competitive interactions, land-use history, or underlying 384 features of the terrain. For example, if dispersal limitation prevents distributional shifts, then we 385 might expect that spatial SDMs would perform better for dispersal-limited taxa (e.g., Tsuga) that 386 cannot track changes in climate, but not necessarily for taxa with effective dispersal vectors (e.g., 
387 Fagus) that can gain dominance by migrating faster to climatically favorable sites (Pearman et 388 al., 2008b). These taxon-specific differences in dispersal mode and degree of dominance could 389 explain why Tsuga seemed to be less responsive to climate over the past 8 millennia than Fagus 390 as evidenced by the better performance over time of the two spatial models in regards to both 391 AUC and FPR for Tsuga, but not for Fagus. Simulation experiments for European trees with 392 spatially explicit process models accounting for changing macroclimate, competition, and habitat 393 connectivity showed that some of the spatial autocorrelation between two time periods may be 394 due to very slow migration rates resulting in severe time lags that are not accounted for in non395 dynamic and non-spatial SDMs (Meier et al., 2012). Also, Dobrowski et al. (2011) found that 396 non-spatial SDMs fit to widespread plants with more effective dispersal mechanisms had higher 397 predictive accuracy over 75 years of climate change in California than non-spatial SDMs fit to 398 dispersal-limited plants.

399 Given the results of this study, should researchers include spatial random effects in 400 SDMs? We found that for two long-lived eastern North American trees, spatial models provided 401 better fits to calibration data and lower FPRs, but not necessarily improvements in AUC or the 402 FNR. The better fits of the spatial SDMs may have resulted from the richness of the FIA data 403 used to calibrate the models. Large samples of evenly-dispersed data likely will capture any 404 spatial structure; consequently a spatial SDM should fit well. However, when sample sizes are 405 small, there is less of a chance that the spatial structure will be represented adequately.

406 Ultimately, whether to include spatial random effects in SDMs will depend on the taxon being 407 modeled, the cost of false positives, and the quality of the data. 
410 This research was supported by the U.S. Department of Energy's National Institute for Climate

411 Change Research, through sub-award 3892-HU-DOE-4157 to AME and MCF, NSF grant DBI

412 10-03938 to AME, and NSF grants DMS-1106609 and EF-1137309 to AOF. FIA data were

413 provided by Brett Butler and Elizabeth LaPoint (both with the U.S. Forest Service) pursuant to a

414 Memorandum of Understanding 09MU11242305123 between the USFS and Harvard University.

415 Eliza Ledwell and Elisabete Baker-Vail assisted with initial data organization and programming.

416 The Harvard Forest Lab Group, J. Williams, N. Zimmerman, and three anonymous reviewers

417 provided valuable insights.

418 Supplementary material

419 Appendix S1 Presence-absence plots of historic pollen distributions.

420 Appendix S2 Detailed description of the models.

421 Appendix S3 Plots of between- and within-time correlations of paleoclimate data.

422 Appendix $\mathbf{S 4}$ Code for analyses programmed in $\mathrm{R}$ and $\mathrm{C}++$.

423 Appendix S5 Results of the Fagus and Tsuga low pollen threshold analysis.

\section{Biosketch}

425 Sydne Record is a post-doctoral research fellow at Harvard University - Harvard Forest with

426 broad research interests in validating ecological models and Bayesian statistics.

427 Author contributions: M.C.F., S.R., and A.M.E. conceived the ideas for the study. S.R., M.C.F., 428 and A.O.F. conducted statistical analyses. S.R. led the writing of the manuscript with critical 429 comments from all co-authors. S.V. provided the downscaled climate data. 
430

431

432

433

434

435

436

437

438

439

440

441

442

443

444

445

446

447

448

449

450

451

452

\section{Literature Cited}

Bahn, V. \& McGill, B.J. (2007) Can niche-based distribution models outperform spatial interpolation? Global Ecology and Biogeography, 16, 733-742.

Bartlein, P.J., Prentice, I.C. \& Webb, T. (1986) Climatic response surfaces from pollen data for some eastern North American taxa. Journal of Biogeography, 13, 35-57.

Bhiry, N. \& Filion, L. (1996) Mid-Holocene decline in eastern North America linked with phytophagous insect activity. Quaternary Research, 45, 312-320.

Bini, L.M., Diniz-Filho, J.A.F., Rangel, T.F.L.V.B., et al. (2009) Coefficient shifts in geographical ecology: an empirical evaluation of spatial and non-spatial regression. Ecography, 32, 193-204.

Blauw, M., Christen, J.A., Mauqouy, D., van der Plicht, J. \& Bennett, K.D. (2007) Testing the timing of radiocarbon-dated events between proxy archives. Holocene, 17, 283-288.

Blois, J.L., Williams, J.W., Grimm, E.C., Jackson, S.T. \& Graham, R.W. (2011) A methodological framework for assessing and reducing temporal uncertainty in paleovegetation mapping from late-Quaternary pollen records. Quaternary Science Reviews, 30, 1926-1939.

Brohan, P., Kennedy, J.J., Harris, I., Tett, S.F.B. \& Jones, P.D. (2006) Uncertainty estimates in regional and global observed temperature changes: a new dataset from 1850. Journal of Geophysical Research, 111, D12106.

Clayton, J.S., Carlin, B.P. \& Montomoli, C. (1993) Spatial correlation in ecological analysis. Journal of Epidemiology, 22, 1193-1201.

Davis, M.B. (1981) Quaternary history and the stability of forest communities. Forest Succession (ed. by D.C. West, H.H. Shugart and D.B. Botkin), pp. 132-153. Springer, New York. 
453 Diez, J.M. \& Pulliam, H.R. (2007) Hierarchical analysis of species distributions and abundance 454 across environmental gradients. Ecology, 88, 3144-3152.

455 Dobrowski, S.Z., Thorne, J.H., Greenberg, J.A., Safford, H.D., Mynsberge, A.R., Crimmins, 456 S.M. \& Swanson, A.K. (2011) Modeling plant distributions over 75 years of measured 457 climate change in California, USA: relating temporal transferability to species traits. $458 \quad$ Ecological Monographs, 81, 241-257.

459 Dormann, C.F. (2007) Effects of incorporating spatial autocorrelation into the analysis of species 460 461 462 463 464 465 466 distribution data. Global Ecology and Biogeography, 16, 129-138.

Elith, J., Kearney, M. \& Phillips, S. (2010) The art of modeling range-shifting species. Methods in Ecology and Evolution, 1, 330-342.

Fitzpatrick, M.C., Weltzin, J.F., Sanders, N.J. \& Dunn, R.R. (2007) The biogeography of prediction error: why does the introduced range of the fire ant over-predict its native range? Global Ecology and Biogeography, 16, 24-33.

Foster, D.R., Oswald, W.W., Faison, E.K., Doughty, E.D. \& Hansen B.C.S. (2006) A climatic driver for abrupt mid-Holocene vegetation dynamics and the hemlock decline in New England. Ecology, 87, 2959-2966.

Franklin, J. \& J.A. Miller. (2009) Mapping species distributions: spatial inference and

471 Gelfand, A.E., Latimer, A., Wu, S. \& Silander, J.A. (2006) Building statistical models to analyze 472 species distributions. Hierarchical Modelling for the Environmental Sciences: Statistical $474 \quad$ University Press, Oxford. 
475 Guisan, A. \& W. Thuiller. (2005) Predicting species distribution: offering more than simple 476 habitat models. Ecology Letters, 8, 993-1009.

477 Hawkins, B.A., Diniz-Filho, J.A.F., Bini, L.M., De Marco, P. \& Blackburn, T.M. (2007) Red 478 herrings revisited: spatial autocorrelation and parameter estimation in geographical $479 \quad$ ecology. Ecography, 30, 375-384.

480 Heikkinen, R.K., Luoto, M., Araújo, M.B., Virkkala, R., Thuiller, W. \& Sykes, M.T. (2006) 481 482 483 484 485 486 Methods and uncertainties in bioclimatic envelope modeling under climate change. Progress in Physical Geography, 30, 751-777.

Hellman, J.J., Prior, K.M. \& Pelini, S.L. (2012) The influence of species interactions on geographic range change under climate change. Annals of the New York Academy of Sciences, 1249, 18-28.

Hijmans, R.J., Cameron, S.E., Parra, J.L., Jones, P.G. \& Jarvis, A. (2005) Very high resolution interpolated climate surfaces for global land areas. Journal of Climatology, 25, 19651978.

Hodges, J.S. \& Reich, B.J. (2010) Adding spatially-correlated errors can mess up the fixed effect you love. American Statistical Association, 64, 325-334.

Kühn, I. (2007) Effects of incorporating spatial autocorrelation into the analysis of species distribution data. Global Ecology and Biogeography, 16, 129-138.

Lee, S., Wolberg, G. \& Shin, S.Y. (1997) Scattered data interpolation with multilevel B-splines. IEEE Transactions on Visualization and Computer Graphics, 3, 229-244.

Legendre, P. (1993) Spatial autocorrelation - trouble or new paradigm. Ecology, 74, 1659-1673. Lichstein, J.W., Simons, T.R., Shriner, S.A. \& Franzreb, K.E. (2002) Spatial autocorrelation and autoregressive models in ecology. Ecological Monographs, 72, 445-463. 
498 Liu, C., Berry, P.M., Dawson, T.P. \& Pearson, R.G. (2005) Selecting thresholds of occurrence in 499 the prediction of species distributions. Ecography, 28, 385-393.

500 Liu, Z., Otto-Bleisner, B.L., He, F., et al. (2009) Transient simulation of last deglaciation with a 501 new mechanism for Bolling-Allerod warming. Science, 325, 310-314.

502 Lobo, J.M., Jiménez-Valverde, A. \& Real, R. (2008) AUC: a misleading measure of the 503 performance of predictive distribution models. Global Ecology and Biogeography, 17, 504 145-151.

505 Meier, E.S., Lischke, H., Schmatz, D.R. \& Zimmerman, N.E. (2012) Climate, competition and 506 connectivity affect future migration and ranges of European trees. Global Ecology and $507 \quad$ Biogeography, 21, 164-178.

508 Merrill, R.M., Gutierrez, D., Lewis, O.T., Gutierrez, J., Diez, S.B. \& Wilson, R.J. (2007) 509 Combined effects of climate and biotic interactions on the elevational range of a $510 \quad$ phytophagous insect. Journal of Animal Ecology, 77, 145-155.

511 Mitchell, T.D. \& Jones, P.D. (2005) An improved method of constructing a database of monthly 512 513 climate observations and associated high-resolution grids. International Journal of Climatology, 25, 305-314.

514 Nogués-Bravo, D. (2009) Predicting the past distribution of species climatic niches. Global $515 \quad$ Ecology and Biogeography, 18, 521-531.

516 Paciorek, C.J. (2010) The importance of scale for spatial-confounding bias and precision of 517 spatial regression estimators. Statistical Science, 25, 107-125.

518 Paciorek, C.J. \& McLachlan, J.S. (2009) Mapping ancient forests: Bayesian inference for spatio519 temporal trends in forest composition using the fossil pollen proxy record. Journal of the $520 \quad$ American Statistical Society, 104, 608-622. 
521 Pearman, P.B., Randin, C.F., Broennimann, et al. (2008a) Prediction of plant species

522 distributions across six millennia. Ecology Letters, 11, 357-369.

523 Pearman, P.B., Guisan, A., Broennimann, O. \& Randin, C.F. (2008b) Niche dynamics in space 524 and time. Trends in Ecology and Evolution, 23, 149-158.

525 Pearson, R.G. \& Dawson, T.P. (2003) Predicting the impacts of climate change on the 526 distribution of species: Are bioclimate envelope models useful? Global Ecology and $527 \quad$ Biogeography, 12, 361-371.

528 Segurado, P., Araújo, M.B. \& Kunin, W.E. (2006) Consequences of spatial autocorrelation for 529 niche-based models. Journal of Applied Ecology, 43, 433-444.

530 Spiegelhalter, D.J., Best, N., Carlin, B.P. \& van der Linde, A. (2002) Bayesian measures of 531 model complexity and fit (with discussion). Journal of the Royal Statistical Society Series

532 $B$, 64, 583-639.

533 Svenning, J.-C. \& Skov, F. (2004) Limited filling of the potential range in European tree species. $534 \quad$ Ecology Letters, 7, 565-573.

535 Thomas, C.D., Bodsworth, E.J., Wilson, R.J., Simmons, A.D., Davis, Z.G., Musche, M. \& 536 Conradt, L. (2001) Ecological and evolutionary processes at expanding range margins. $537 \quad$ Nature, 411, 577-581.

538 Veloz, S.D., Williams, J.W., Blois, J.L., He, F., Otto-Bliesner, B. \& Liu, Z. (2012) No-analog 539 climates and shifting realized niches during the late Quaternary: implications for $21^{\text {st }}$ century predictions by species distribution models. Global Change Biology, 18, 1698-

541 1713.

542 Warren, M.S., Hill, J.K., Asher, T.J., Fox, R., Huntley, B., Roy, D.B., Telfer, M.G., Jeffcoate, S., 543 Harding, P., Jeffcoate, G., Willis, S.G., Greatorex-Davies, J.N., Moss, D. \& Thomas, C.D. 

change. Nature, 414, 65-69.

546 Wilby, R.L., Charles, S.P., Zorita, E., Timbal, B., Whetton, P. \& Mearns, L.O. (2004) Guidelines

547 for use of climate scenarios developed from statistical downscaling methods. IPCC Task

548 Group on data and scenario support for Impact and Climate Analysis (TGICA), pp. 1-27.

549 Williams, J.W., Blois, J.L. \& Shuman, B.N. (2011) Extrinsic and intrinsic forcing of abrupt

550 ecological change: case studies from the late Quaternary. Journal of Ecology, 99, 664-

$551 \quad 677$.

552 Wilson, T.L., Odei, J.B., Hooten, M.B. \& Edwards, T.C. (2010) Hierarchical spatial models for 553 predicting pygmy rabbit distribution and relative abundance. Journal of Applied Ecology, $554 \quad 47,401-409$.

555 Woodward, F.I. (1990) The impact of low temperatures in controlling the geographical 556 distribution of plants. Philosophical Transactions of the Royal Society of London B, 326, $557 \quad 585-593$

558 Woudenberg, S.W., Conkling, B.L., O'Connell, B.M., LaPoint, E.B., Turner, J.A. \& Waddell, 559 K.L. (2010) The Forest Inventory and Analysis Database: Database description and user's 560 manual version 4.0 for Phase 2. Gen. Tech. Rep. RMRS-GTR- 245. Fort Collins, CO:

561 U.S. Department of Agriculture, Forest Service, Rocky Mountain Research Station. 336 562 p. 
563 Table 1. Parameter credible intervals $(2.5 \%, 50.0 \%$, and $97.5 \%$ percentiles) for the Fagus

564 spatially-varying intercept (SVI), non-spatial (NS2 and NS4) and SVI plus climate (SVI2 and

565 SVI4) models. The numbers two and four in the acronyms for the non-spatial and SVI plus

566 climate models indicate the number of bioclimatic explanatory variables included in the models.

567 The two climatic variables models included annual mean temperature (BIO1) and precipitation

568 seasonality (BIO15). The four climatic variables models included annual mean temperature

569 (BIO1), mean diurnal range (BIO2), annual precipitation (BIO12), and precipitation seasonality

570 (BIO15). For models with spatial random effects, the spatial random effect variance and spatial

571 decay parameter are denoted $\sigma^{2}$ and $\varphi$, respectively.

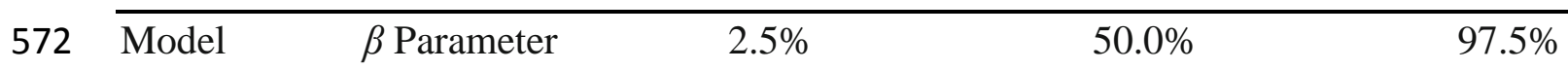

573

$\begin{array}{llllll}574 & \text { SVI } & \text { Intercept } & -7.23 & -5.28 & -2.72 \\ 575 & \text { SVI } & \sigma^{2} & 8.11 & 12.90 & 20.24 \\ 576 & \text { SVI } & \varphi & 1.0910^{-6} & 1.6210^{-6} & 2.6310^{-6} \\ 577 & \text { NS2 } & \text { Intercept } & -3.06 & -3.01 & -2.96 \\ 578 & \text { NS2 } & \text { BIO1 } & -0.48 & -0.46 & -0.43 \\ 579 & \text { NS2 } & \text { BIO15 } & -1.83 & -1.78 & -1.72 \\ 580 & \text { NS4 } & \text { Intercept } & -3.11 & -3.06 & -3.01 \\ 581 & \text { NS4 } & \text { BIO1 } & -0.62 & -0.58 & -0.54 \\ 582 & \text { NS4 } & \text { BIO2 } & 0.33 & 0.37 & 0.40 \\ 583 & \text { NS4 } & \text { BIO12 } & -0.20 & -0.14 & -0.09 \\ 584 & \text { NS4 } & \text { BIO15 } & -2.03 & -1.96 & -1.90 \\ 585 & \text { SVI2 } & \text { Intercept } & -7.49 & -5.77 & -4.41\end{array}$




\begin{tabular}{|c|c|c|c|c|c|}
\hline 586 & SVI2 & BIO1 & -1.57 & -1.25 & -0.89 \\
\hline 587 & SVI2 & BIO15 & -0.97 & -0.47 & -0.08 \\
\hline 588 & SVI2 & $\sigma^{2}$ & 6.35 & 10.32 & 17.25 \\
\hline 589 & SVI 2 & $\varphi$ & $1.1510^{-6}$ & $1.9010^{-6}$ & $3.2010^{-6}$ \\
\hline 590 & SVI 4 & Intercept & -8.27 & -5.47 & -3.13 \\
\hline 591 & SVI 4 & BIO1 & -1.37 & -0.83 & -0.25 \\
\hline 592 & SVI 4 & $\mathrm{BIO} 2$ & -0.16 & -0.03 & -0.11 \\
\hline 593 & SVI 4 & BIO12 & -0.15 & -0.47 & 0.80 \\
\hline 594 & SVI 4 & BIO15 & -0.89 & -0.36 & -0.12 \\
\hline 595 & SVI 4 & $\sigma^{2}$ & 5.53 & 10.50 & 17.78 \\
\hline 596 & SVI 4 & $\varphi$ & $1.1410^{-6}$ & $1.9110^{-6}$ & $3.6910^{-6}$ \\
\hline
\end{tabular}


598 Table 2. Parameter credible intervals $(2.5 \%, 50 \%$, and $97.5 \%$ percentiles) for the Tsuga spatially599 varying intercept (SVI), non-spatial (NS2 and NS4) and SVI plus climate (SVI 2 and SVI 4)

600 models. The numbers two and four in the acronyms for the non-spatial and SVI plus climate

601 models indicate the number of bioclimatic explanatory variables included in the models. The two

602 climatic variables models included annual mean temperature (BIO1) and precipitation

603 seasonality (BIO15). The four climatic variables models included annual mean temperature

604 (BIO1), mean diurnal range (BIO2), annual precipitation (BIO12), and precipitation seasonality

605 (BIO15). For models with spatial random effects, the spatial random effect variance and spatial

606 decay parameter are denoted $\sigma^{2}$ and $\varphi$, respectively.

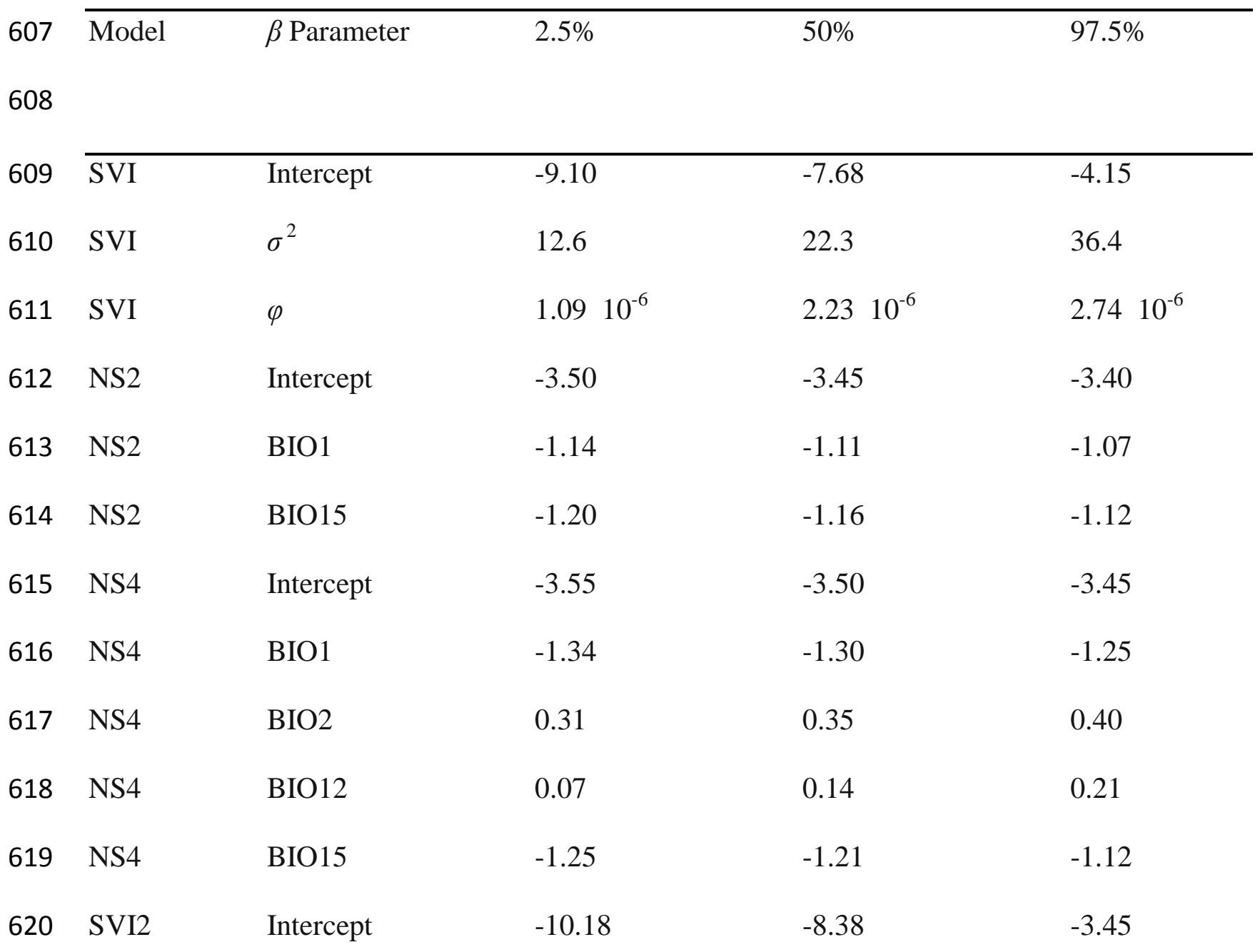




\begin{tabular}{|c|c|c|c|c|}
\hline 621 SVI 2 & BIO1 & 0.07 & 0.48 & 0.89 \\
\hline 622 SVI 2 & BIO15 & -1.09 & -0.55 & -0.05 \\
\hline 623 SVI 2 & $\sigma^{2}$ & 10.86 & 18.57 & 32.11 \\
\hline 624 SVI 2 & $\varphi$ & $1.0910^{-6}$ & $1.6810^{-6}$ & $2.9610^{-6}$ \\
\hline $625 \quad$ SVI 4 & Intercept & -8.28 & -5.73 & -4.00 \\
\hline 626 SVI 4 & BIO1 & -1.28 & -0.85 & -0.26 \\
\hline 627 SVI 4 & $\mathrm{BIO} 2$ & -0.16 & -0.03 & 0.11 \\
\hline SVI 4 & BIO12 & -0.15 & 0.47 & 0.80 \\
\hline SVI 4 & BIO15 & -0.81 & -0.36 & 0.12 \\
\hline SVI 4 & $\sigma^{2}$ & 5.94 & 10.58 & 17.86 \\
\hline $31 \quad$ SVI 4 & $\varphi$ & $1.1410^{-6}$ & $1.8910^{-6}$ & $3.4310^{-6}$ \\
\hline
\end{tabular}


633 Table 3. Fits of the spatially-varying intercept (SVI), non-spatial, and SVI plus climate SDMs to

634 the modern Forest Inventory and Analysis (FIA) occurrence data for Fagus and Tsuga.

635 Bioclimatic variables included in the models with climatic predictors were: annual mean

636 temperature (BIO1), mean diurnal range (BIO2), annual precipitation (BIO12), and precipitation

637 seasonality (BIO15). Model fit was evaluated with the Deviance Information Criterion (DIC),

638 which is the sum of $P_{D}$ (the effective number of parameters) and the posterior mean of the

639 deviance. To facilitate model comparison, $\triangle \mathrm{DIC}$ was also calculated, where the model with the

640 lowest DIC has a value of zero and all other models are compared to it.

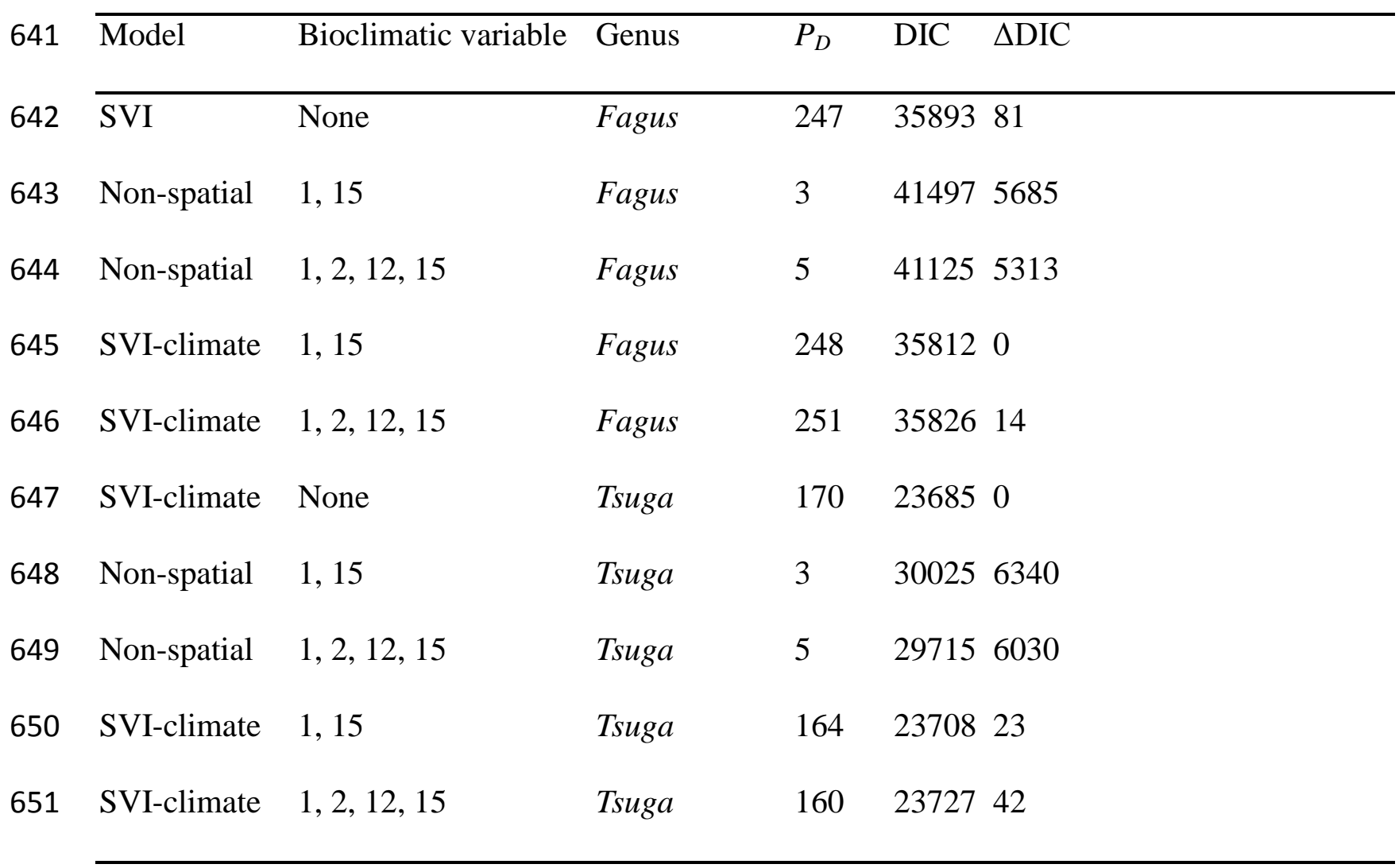


Table 4. Model performance as measured by Area Under the Receiver Operating Curve (AUC), false negative rates (FNR), and false positive rates (FPR) for the non-spatial model, spatiallyvarying intercept (SVI) model, SVI plus climate, and multilevel B-spline fit to modern Fagus and Tsuga occurrence data from the Forest Inventory and Analysis (FIA) data. Predictions of the models for modern time were validated with a $10 \%$ hold-out dataset from the FIA data.

Hindcasts were validated with data from the fossil pollen record provided by the Neotoma database using the "high" pollen thresholds for both genera. The numbers behind the AUC, FNR, and FPR values in parentheses for the Bayesian models represent the standard error calculated from 1000 random draws from the post burn-in MCMC iterations. For the FIA multilevel Bspline approximation there is no standard error as there were no MCMC iterations to draw from.

\begin{tabular}{|c|c|c|c|c|c|c|}
\hline \multicolumn{3}{|c|}{$\begin{array}{l}\text { Genus Performance Time } \\
\end{array}$} & \multirow[t]{2}{*}{ Non-spatial } & \multirow[t]{2}{*}{ SVI } & \multirow[t]{2}{*}{ SVI-climate } & \multirow[t]{2}{*}{ FIA } \\
\hline & Measure & (kaBP) & & & & \\
\hline \multirow[t]{9}{*}{$\overline{\text { Fagus }}$} & AUC & 0 & $0.87\left(4 \times 10^{-4}\right)$ & $0.91(0.01)$ & $0.92(0.01)$ & 0.91 \\
\hline & & 1 & $0.89\left(5 \times 10^{-4}\right)$ & $0.87(0.02)$ & $0.87(0.02)$ & 0.86 \\
\hline & & 2 & $0.90\left(4 \times 10^{-4}\right)$ & $0.88(0.02)$ & $0.88(0.02)$ & 0.86 \\
\hline & & 3 & $0.89\left(6 \times 10^{-4}\right)$ & $0.88(0.01)$ & $0.88(0.02)$ & 0.86 \\
\hline & & 4 & $0.88\left(6 \times 10^{-4}\right)$ & $0.87(0.02)$ & $0.87(0.02)$ & 0.84 \\
\hline & & 5 & $0.85\left(1 \times 10^{-3}\right)$ & $0.85(0.02)$ & $0.84(0.02)$ & 0.83 \\
\hline & & 6 & $0.84\left(2 \times 10^{-3}\right)$ & $0.84(0.02)$ & $0.83(0.03)$ & 0.83 \\
\hline & & 7 & $0.81\left(1 \times 10^{-3}\right)$ & $0.80(0.02)$ & $0.80(0.03)$ & 0.78 \\
\hline & & 8 & $0.73\left(2 \times 10^{-3}\right)$ & $0.76(0.01)$ & $0.74(0.02)$ & 0.71 \\
\hline \multirow[t]{2}{*}{ Fagus } & FNR & 0 & $0.22(0.01)$ & $0.14(0.04)$ & $0.14(0.03)$ & 0.11 \\
\hline & & 1 & $0.20(0.01)$ & $0.23(0.04)$ & $0.22(0.09)$ & 0.26 \\
\hline
\end{tabular}




\begin{tabular}{|c|c|c|c|c|c|}
\hline & 2 & $0.19(0.02)$ & $0.21(0.05)$ & $0.20(0.09)$ & 0.24 \\
\hline & 3 & $0.19(0.01)$ & $0.19(0.04)$ & $0.21(0.09)$ & 0.23 \\
\hline & 4 & $0.22(0.01)$ & $0.20(0.04)$ & $0.22(0.09)$ & 0.23 \\
\hline & 5 & $0.28(0.02)$ & $0.24(0.04)$ & $0.25(0.10)$ & 0.26 \\
\hline & 6 & $0.26(0.01)$ & $0.25(0.05)$ & $0.27(0.10)$ & 0.24 \\
\hline & 7 & $0.30(0.01)$ & $0.31(0.05)$ & $0.32(0.10)$ & 0.31 \\
\hline & 8 & $0.34(0.03)$ & $0.33(0.04)$ & $0.35(0.07)$ & 0.38 \\
\hline Fagus FPR & 0 & $0.23(0.01)$ & $0.14(0.02)$ & $0.14(0.02)$ & 0.12 \\
\hline & 1 & $0.21(0.02)$ & $0.23(0.04)$ & $0.22(0.05)$ & 0.23 \\
\hline & 2 & $0.20(0.02)$ & $0.21(0.04)$ & $0.20(0.06)$ & 0.22 \\
\hline & 3 & $0.20(0.01)$ & $0.19(0.03)$ & $0.21(0.06)$ & 0.22 \\
\hline & 4 & $0.24(0.02)$ & $0.19(0.04)$ & $0.22(0.07)$ & 0.25 \\
\hline & 5 & $0.28(0.03)$ & $0.24(0.03)$ & $0.25(0.07)$ & 0.26 \\
\hline & 6 & $0.27(0.02)$ & $0.25(0.04)$ & $0.26(0.07)$ & 0.28 \\
\hline & 7 & $0.26(0.02)$ & $0.31(0.04)$ & $0.30(0.07)$ & 0.29 \\
\hline & 8 & $0.35(0.01)$ & $0.33(0.04)$ & $0.34(0.07)$ & 0.40 \\
\hline Tsuga AUC & 0 & $0.85\left(3 \times 10^{-3}\right)$ & $0.95(0.02)$ & $0.95\left(8 \times 10^{-3}\right)$ & 0.97 \\
\hline & 1 & $0.85\left(3 \times 10^{-3}\right)$ & $0.91(0.01)$ & $0.91(0.02)$ & 0.82 \\
\hline & 2 & $0.86\left(4 \times 10^{-4}\right)$ & $0.89(0.01)$ & $0.89(0.02)$ & 0.81 \\
\hline & 3 & $0.87\left(4 \times 10^{-4}\right)$ & $0.88(0.01)$ & $0.87(0.02)$ & 0.80 \\
\hline & 4 & $0.83\left(3 \times 10^{-3}\right)$ & $0.86(0.02)$ & $0.85(0.02)$ & 0.80 \\
\hline & 5 & $0.84\left(3 \times 10^{-3}\right)$ & $0.90(0.02)$ & $0.89(0.02)$ & 0.84 \\
\hline & 6 & $0.86\left(2 \times 10^{-3}\right)$ & $0.91(0.02)$ & $0.90(0.02)$ & 0.80 \\
\hline
\end{tabular}




\begin{tabular}{|c|c|c|c|c|c|}
\hline & 7 & $0.85\left(5 \times 10^{-3}\right)$ & $0.88(0.02)$ & $0.87(0.02)$ & 0.80 \\
\hline & 8 & $0.76\left(5 \times 10^{-3}\right)$ & $0.89(0.02)$ & $0.88(0.02)$ & 0.79 \\
\hline \multirow[t]{9}{*}{ Tsuga FNR } & 0 & $0.20(0.03)$ & $0.11(0.04)$ & $0.11(0.04)$ & 0.05 \\
\hline & 1 & $0.16(0.07)$ & $0.16(0.04)$ & $0.18(0.03)$ & 0.20 \\
\hline & 2 & $0.19(0.02)$ & $0.18(0.04)$ & $0.20(0.03)$ & 0.21 \\
\hline & 3 & $0.19(0.03)$ & $0.18(0.04)$ & $0.20(0.04)$ & 0.20 \\
\hline & 4 & $0.21\left(3 \times 10^{-3}\right)$ & $0.20(0.05)$ & $0.21(0.04)$ & 0.21 \\
\hline & 5 & $0.25(0.02)$ & $0.17(0.04)$ & $0.18(0.04)$ & 0.20 \\
\hline & 6 & $0.20(0.02)$ & $0.16(0.04)$ & $0.18(0.03)$ & 0.20 \\
\hline & 7 & $0.25(0.01)$ & $0.18(0.04)$ & $0.19(0.03)$ & 0.24 \\
\hline & 8 & $0.30(0.01)$ & $0.19(0.05)$ & $0.19(0.04)$ & 0.33 \\
\hline \multirow[t]{9}{*}{ Tsuga FPR } & 0 & $0.22(0.01)$ & $0.11(0.03)$ & $0.11(0.03)$ & 0.09 \\
\hline & 1 & $0.19(0.03)$ & $0.16(0.04)$ & $0.17(0.04)$ & 0.23 \\
\hline & 2 & $0.16(0.01)$ & $0.18(0.04)$ & $0.19(0.03)$ & 0.20 \\
\hline & 3 & $0.19\left(1 \times 10^{-3}\right)$ & $0.18(0.04)$ & $0.19(0.03)$ & 0.22 \\
\hline & 4 & $0.23(0.01)$ & $0.20(0.03)$ & $0.21(0.03)$ & 0.26 \\
\hline & 5 & $0.24(0.02)$ & $0.17(0.04)$ & $0.18(0.04)$ & 0.23 \\
\hline & 6 & $0.19(0.01)$ & $0.16(0.05)$ & $0.17(0.04)$ & 0.18 \\
\hline & 7 & $0.23(0.01)$ & $0.18(0.04)$ & $0.18(0.03)$ & 0.22 \\
\hline & 8 & $0.32(0.01)$ & $0.20(0.04)$ & $0.21(0.03)$ & 0.31 \\
\hline
\end{tabular}


Figure 1. Map of the study extent in the eastern United States showing Forest Inventory and Analysis (FIA) plots (hollow circles) and Neotoma pollen sites (solid triangles) snapped to a resolution of 0.5-degrees (Alber's Equal Area Conic projection).

Figure 2. Numbers of sites with presences (black fill) or absences (white fill) of Fagus (a and c) and Tsuga (b and d) based on the low and high pollen thresholds from present to 21 kiloannums before present $(\mathrm{kaBP})$ based on fossil pollen data from the Neotoma database. Data extending beyond $8 \mathrm{kaBP}$ were not used in the analyses due to the low number of presences of Fagus and Tsuga beyond that time.

Figure 3. Maps of a) a surface approximation of the probability of occurrence of Fagus generated by a multilevel B-spline fit to the raw FIA data and the predicted probability of presence of the b) non-spatial, c) spatially-varying intercept, and d) spatially-varying intercept plus climate SDMs to modern Fagus FIA data (Alber's Equal Area Conic Projection). The surface approximation in a) was calculated with the MBA package in $\mathrm{R}$.

Figure 4. Maps of a) a surface approximation of the probability of occurrence of Tsuga generated by a multilevel B-spline fit to the raw FIA data and the predicted probability of presence of the b) non-spatial, c) spatially-varying intercept, and d) spatially-varying intercept plus climate SDMs to modern Tsuga FIA data (Alber's Equal Area Conic Projection). The surface approximation in a) was calculated with the MBA package in $\mathrm{R}$. 


\section{Study extent}

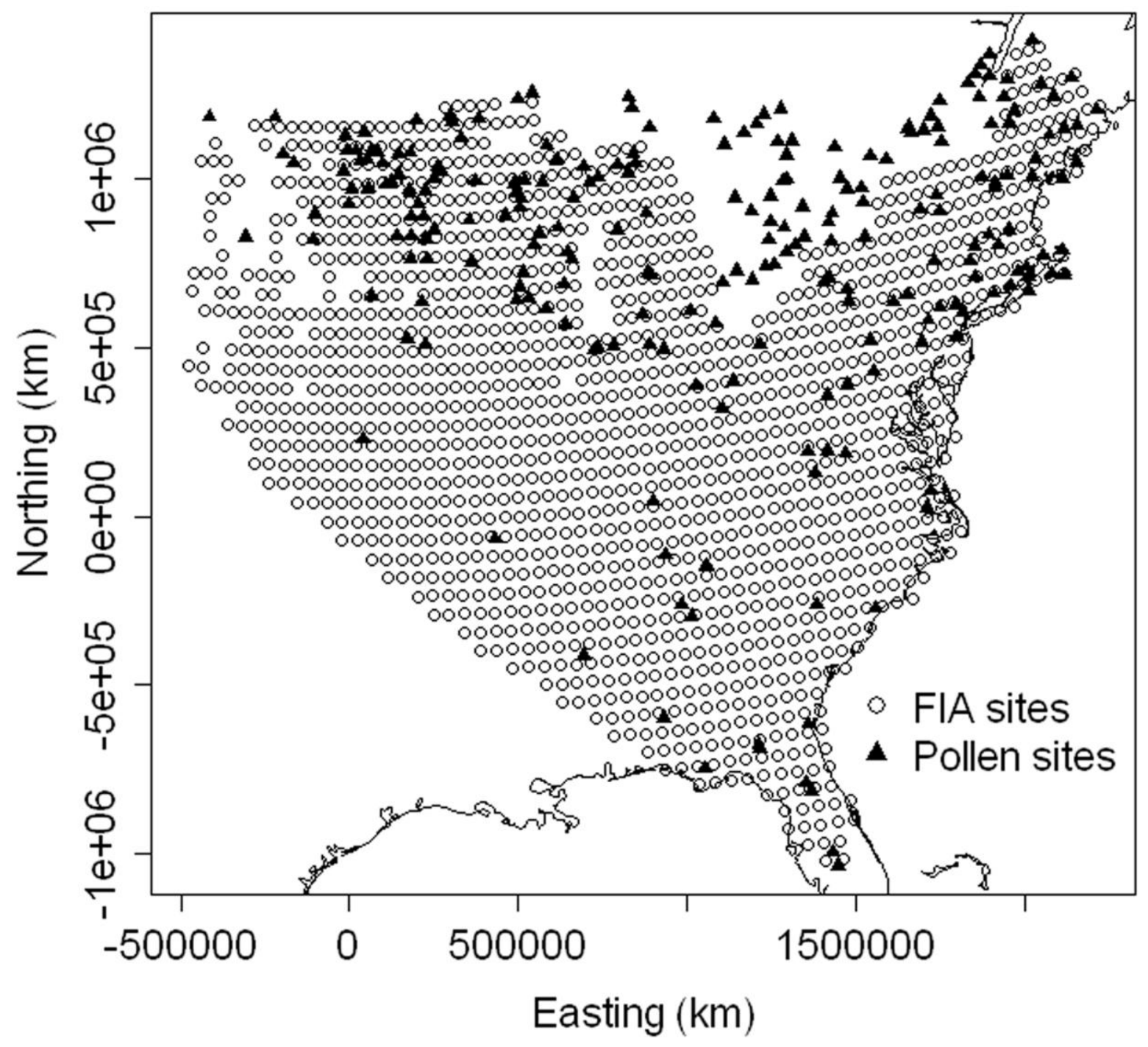

Figure 1 

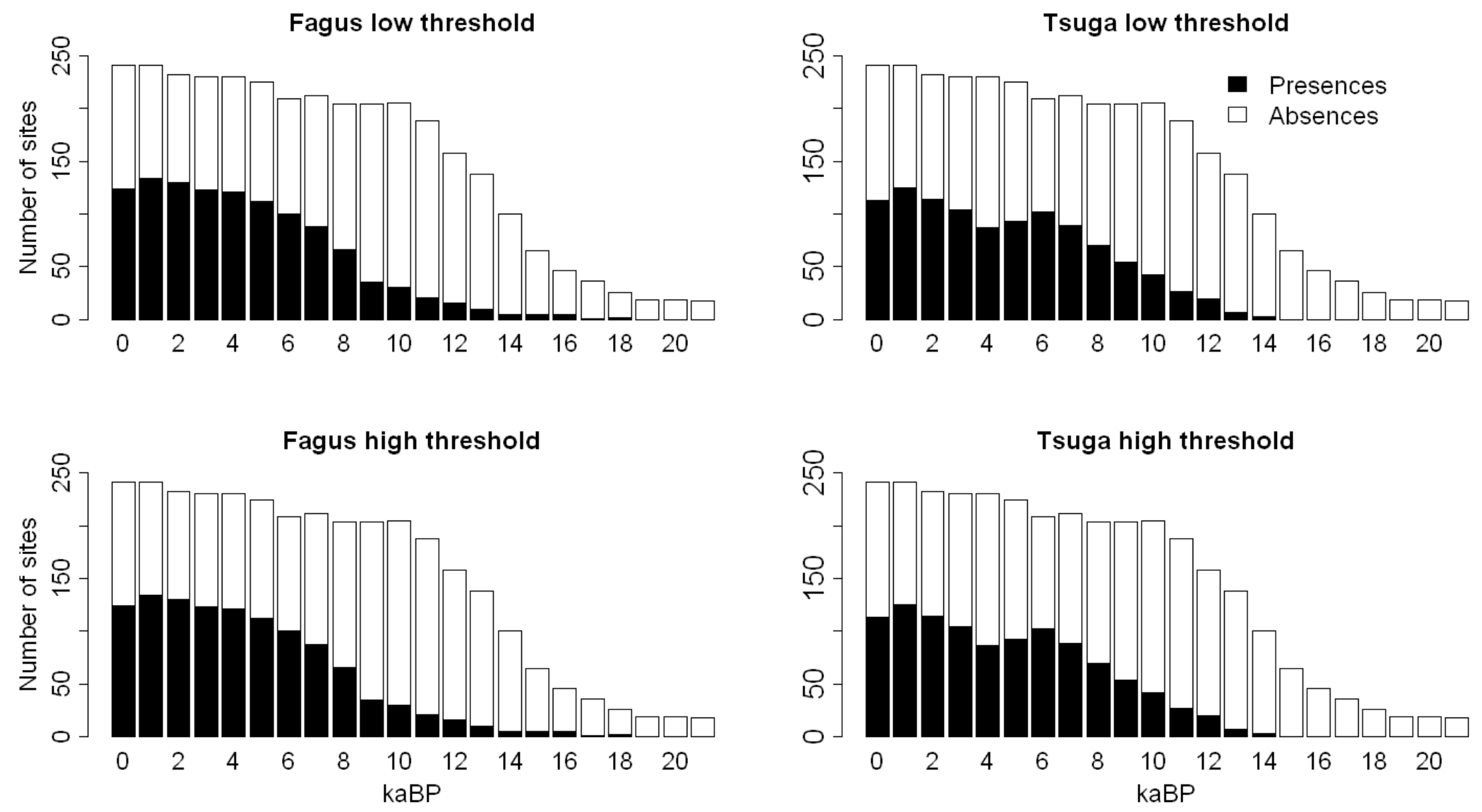

Figure 2 


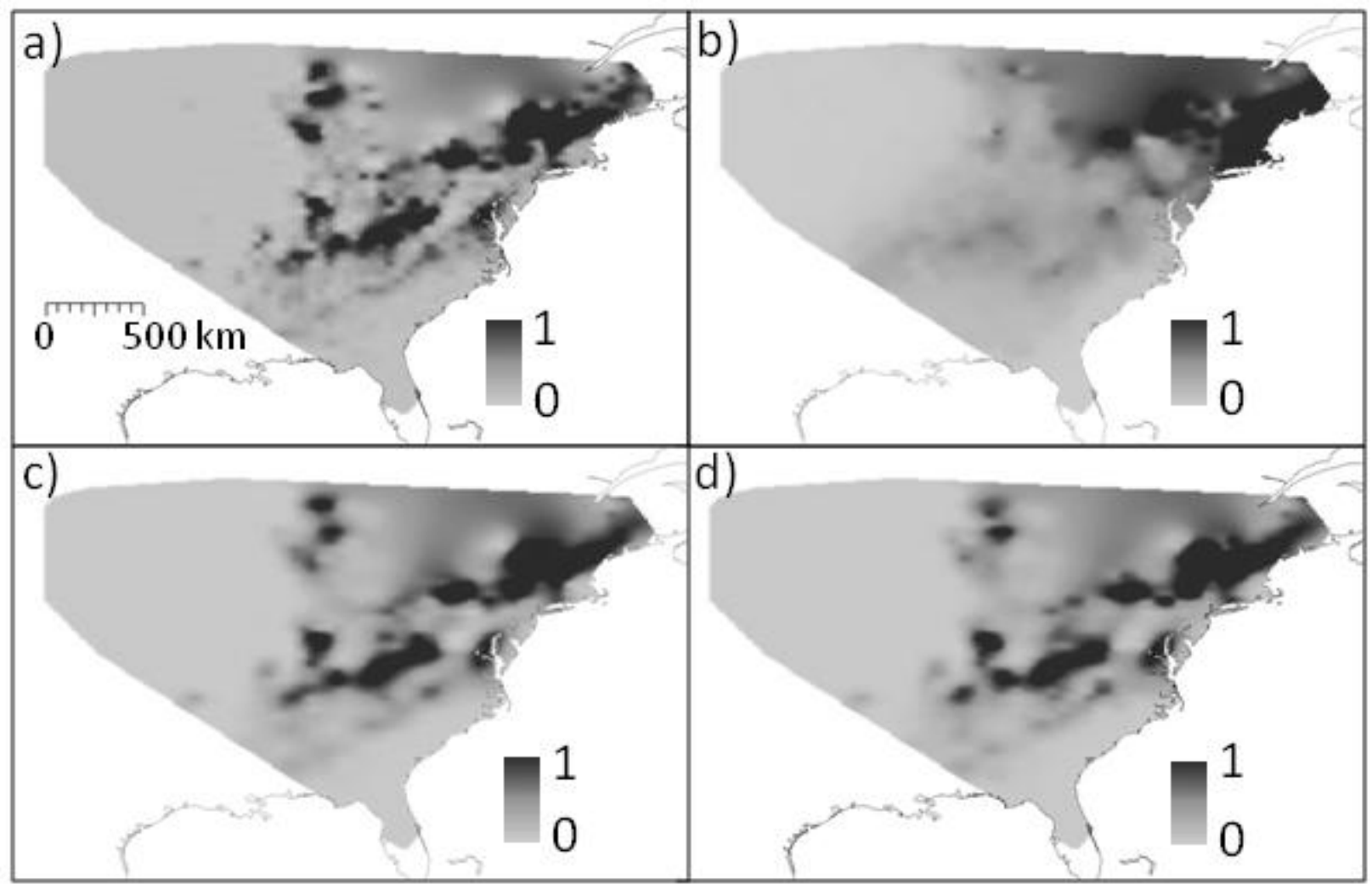

Figure 3 


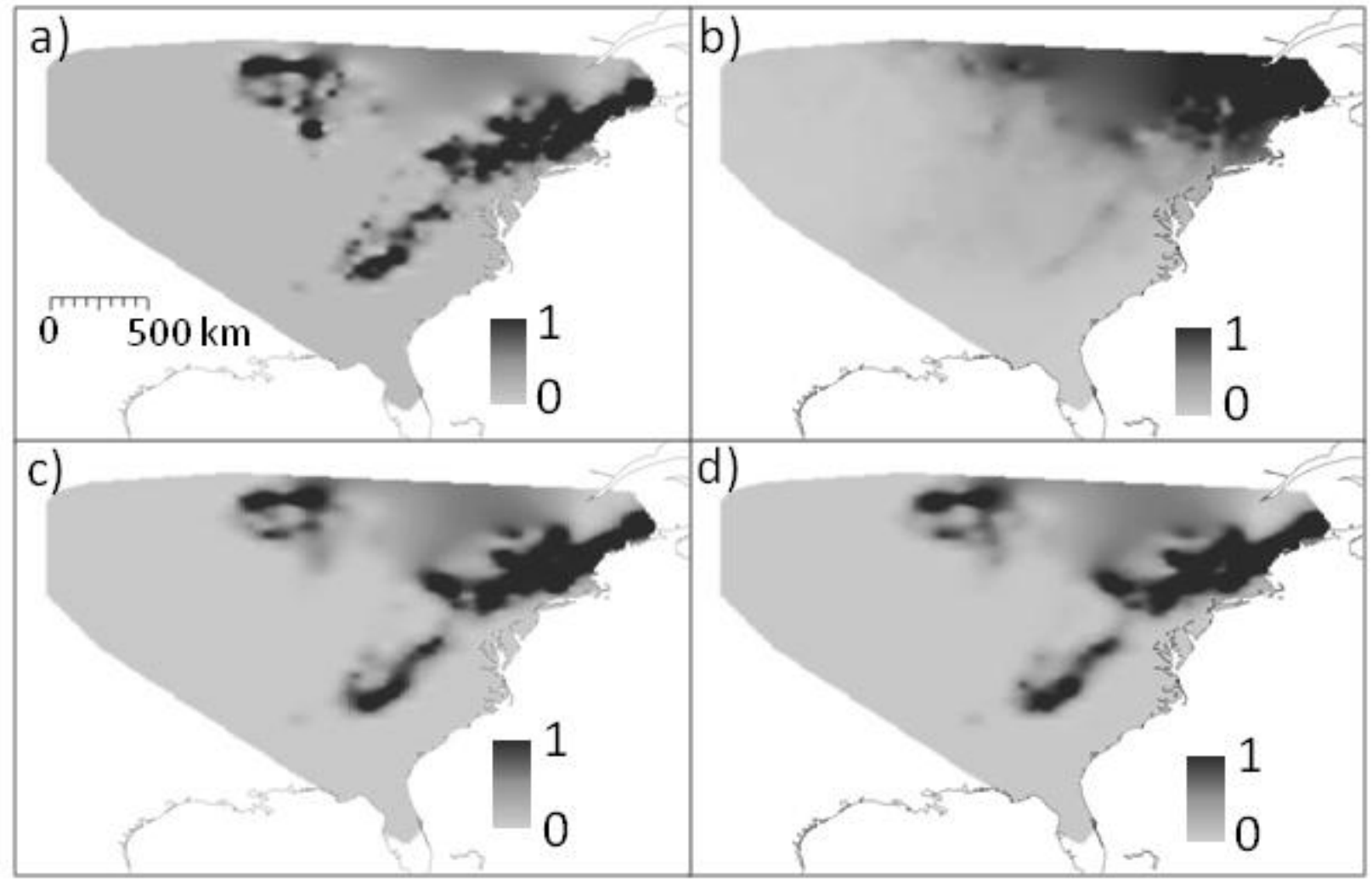

Figure 4 